\title{
NEW ISSUES IN ORCHID CONSERVATION
}

\author{
PAVEL KINDLMANN
}

Department of Biodiversity Research, Global Change Research Centre AS CR, Na Sádkách 7, České Budějovice, Czech Republic and Institute for Environmental Studies, Faculty of Science, Charles University, Benátská 2, Prague, Czech Republic. E-mail: pavel.kindlmann@centrum.cz

The family Orchidaceae with approximately $17,000-35,000$ species is considered to be one of the largest families in the plant kingdom (Atwood 1986; Dressler 1993). Even though this family is evolutionarily young, orchids show an extraordinary diversity of epiphytic and terrestrial growth forms and have successfully colonized almost every habitat on the Earth. However, mainly because of human activities, many species of orchids are now being seriously endangered by extinction. Ways have to be found, how to prevent this trend. Papers in this issue are therefore devoted to various aspects of orchid conservation. Many of them were presented at the 4th International Congress on Orchid Conservation, which was held in Hluboká, Czech Republic, May 29-June 6, 2011. This congress followed on from the successful congresses held in Perth (Western Australia) in 2001, Sarasota (Florida) in 2004 and San José (Costa Rica) in 2007.

The congress was dedicated to "Orchids in a Changing World". This is because we are now experiencing dramatic changes in most aspects of our life. Modern technologies are being devised and deployed with increasing frequency; although they make our lives easier, their consequences, such as pollution of air, soil and water, greatly increase the pressure on our already stressed environment. To keep up with the rapidly growing human population, agricultural practices tend to be more and more intensive, which has a negative effect on biodiversity in agricultural landscape. Due to human activities, global temperature is increasing, with unpredictable consequences on ecosystems.

Five papers are devoted to conservation recommendations and analyses of decline of orchids in various parts of the world: European Russia, France, Crete, Singapore and Mexico. As orchid propagation and germination is an important issue in their conservation, six papers deal with these topics. Mycorrhizal fungi, influence of insect herbivores, morphological variability and fragrances complete the issue.

\section{REFERENCES}

Attwood JT (1986) The size of the Orchidaceae and the systematic distribution of epiphytic orchids. Selbyana 9: 171-186.

Dressler RL (1993) Phylogeny and classification of the orchid family. Dioscorides Press. 